\title{
The Strength of Polylactic Acid Composites Reinforced with Sugarcane Bagasse and Rice Husk
}

by Julianj Anggono

Submission date: 20-Jul-2019 10:07AM (UTC+0700)

Submission ID: 1153353767

File name: Paper-QiR_JA_revise15_Jul_2019.pdf (1,002.93K)

Word count: 3282

Character count: 17016 


\title{
The Strength of Polylactic Acid Composites Reinforced with Sugarcane Bagasse and Rice Husk
}

\author{
JULIANA Anggono ${ }^{1, a *)}$, BILY Budiarto ${ }^{1, b}$, SUWANDI Sugondo ${ }^{1, c}$, HARIYATI \\ Purwaningsih ${ }^{2, d}$, and ANTONI ${ }^{3, e}$ \\ ${ }^{1}$ Mechanical Engineering Department, Petra Christian University, Jalan Siwalankerto 121-131, \\ Surabaya 60236, Indonesia \\ ${ }^{2}$ Materials and Metallurgical Engineering Department - Sepuluh Nopember Institute of \\ $11 \quad$ Technology, Surabaya 60111, Indonesia \\ ${ }^{3}$ Civil Engineering Department, Petra Christian University, Jalan Siwalankerto 121-131, Surabaya \\ 60236, Indonesia \\ a"julianaa@petra.ac.id, bm24414009@john.petra.ac.id, caeusug@indo.net.id, dhariyati@mat- \\ eng.its.ac.id, eantoni@petra.ac.id
}

Keywords: green composites, natural fibers, flexural strength, alkali treatment, steam treatment.

\begin{abstract}
There are more than 1000 species of cellulose plants available in fiber for 4 . A number of them are by-products from the major food crops contain lignocellulosic sources and being investigated as composite reinforcement materials. Sugarcane bagasse and rice husk are potential reinforcement materials and they were used to reinforce polylactic acid (PLA) matrix to make green composites. In this research work, sugarcane bagasse was given two different kinds of treatment; some were alkali treated using $8 \mathrm{wt} . \% \mathrm{NaOH}$ at room temperature for an hour and some other were steam treated at $0.75 \mathrm{MPa}$ for 30 minutes. The fiber content of the composites changed with weight percentage ratios of sugarcane bagasse/rice husk/PLA was 25/0/75, 25/5/70 and 25/10/65. Flexural strength was tested in accordance with ASTM D790-17 and structural evaluation was evaluated using scanning electron microscope (SEM) on the fracture section of the flexural test samples. Composites produced using steam treated sugarcane bagasse and rice husk have lower area density $\left(1277-1385 \mathrm{~g} / \mathrm{m}^{2}\right)$ compared to the ones formed using $\mathrm{NaOH}$ treated bagasse and rice husk (1162$1500 \mathrm{~g} / \mathrm{m}^{2}$ ). Both values of area density are below the density of neat PP and wood flour reinforced PP/PE composites used as reference materials. The flexural test shows the $\mathrm{NaOH}$ treatment on the bagasse fibers improve the flexural strength of the composites but the rice husk content introduced to the structure reduces the strength of the composites. SEM evaluation shows fiber fracture and few pull-out.
\end{abstract}

\section{Introduction}

In the recent decade, the environmental issues and the increased environmental awareness of the public have confronted the industry to be producing green products. For example the automotive industry responded by focusing the vehicle materials on biobased materials. Natural fiber composites (NFC) are one of the materials that have low carbon footprint in their production, biodegradable, recyclable, sustainable, and lightweight. Lightweight materials are the keen interest of automotive industry. Material substitution, in specific the use of polymer composites reinforced with natural fibers (biocomposites) has led to massive weight savings. The other major advantages of biocomposites are to achieve increase in stiffness, strength and impact resistance or all at the same time. [1-3] One of the essential pathways to enhance the performance of biocomposites is to improve the properties of the fibers before incorporating them into the polymeric matrix. The properties prepared from neat natural fibers are often rather poor [4], because of weak interactions 
between the fibers and the polymer and/or due to the small perpendicular strength of these lignocellulosic reinforcements [4]. Interactions can be improved by surface modification, while the inherent strength of the reinforcement increases by variqo's treatments [5]. Numerous reports have been published in the literature showing the beneficial effect of alkali treatment of lignocellulosic fibers on the properties of their composites [6-11]. Hardly any or very limited explanation has been given for the phenomenon in most cases.

Alkali treatment, or mercerization, is an old 3 ethod and one of the most common cellulose fiber modification. During alkali treatment, the fibers are soaked in $\mathrm{NaOH}$ solutio 3 of certain concentration for a given period of time and at a given temperature. The solution may activate hydroxyl groups or introduce new moieties that can effectively interlock with the matrix. The advance of a comprehensive theory for the mechanism of bonding by chemicals in composites is a complex problem. Mercerization has a significant effect on changes in crystallinity, fineness, dimension, surface area, and density of the fibers. These clinges may result in improvement in fiber strength and hence stronger composite materials [12, 13]. Mwaikambo et al. [13] reported the effect of mercerization on the mechanical properties of hemp fibers and identified that maximum tensile strength of hemp fibers (1050 MPa) was obtained when the concentration of $\mathrm{NaOH}$ used was $6 \%$ and the use of $\mathrm{NaOH}$ concentration of $4 \%$ resulted in the maximum Young Modulus of hemp fibres $(65 \mathrm{GPa})$. Other method to treat natural fibers to improve interfacial bonding between fiber and polymer matrix is steam treatment. The fibers were steamed above boiling water in a covered tank at a certain steam pressure for few hours. Munawar et al. [14] employe 3 steam treatment of ramie fiber at a steam pressure of $0.1 \mathrm{MPa}$ for two hours. They reported a significantly improved the interfacial adhesion between ramie fiber and polyformaldehyde resin and also the flexural properties of the composites.

Jute, hemp, flax and kenaf fibers have been commercialized or used as reinforcement in large quantity. Other potential fibers come from by-products from the major food crop such as sugarcane and rice husk have been studied as sources for fibers [3, 15-17]. Anggono et al. [15] reported a good flexural strength of $25 \mathrm{wt} . \% \mathrm{NaOH}$ treated sugarcane bagasse-PP composites. The flexural strength obtained was $35.39-37.78 \mathrm{MPa}$ which this strength is similar to the woodboard composites contained $30 \mathrm{wt} . \%$ wood particles in PP which is used 75 current interior automotive product by the industry. Petchwattana and Covavisaruch found the tensile strength of the composites increases from $31.5 \mathrm{MPa}$ (without rice husk) to $44.7 \mathrm{MPa}$ with the rice husk content as many as 60 parts per 100 resin (phr) [17].

Although over a decade, there have been research in biocomposites which has demonstrated such advantages of cellulosic fibers as excellent stiffness and strength, this has not led to the hoped-for range of applications due to factors such as poor compatibility between biofiber and polymer matrix. The main problem is the fibers are hydrophilic and tend to cluster and not disperse well in the matrix. Giving surface treatment to the fibre can reduce waxes and amorphous content and enhance its interfacial adhesion. In this work, a mixture of rice husk and sugarcane fibers was selected as the reinforcement for polylactic acid (PLA) polymer. They both are grown in Indonesia. With sugarcane and rice husk production, Indonesia is in the ninth and third place producer of sugarcane and rice huf respectively $[18,19]$ Rice husk was selected as reinforcement due to its chemical composition is sufficiently close to that of wood so that they can be a suitable alternative reinforcement material to wood fibers for composites. Steam treatment which was more environmental friendly was introduced and compared with the results obtained from alkali treatment. Rice hisk and sugarcane bagasse contain $45 \%$ [20] and $45-55 \%$ cellulose [21] respectively. The combination of PLA with natural reinforcement materials is a good way to produce compostable material thus the stu 9 of the structure and properties of such composites will draw high scientific and practical interest. The goal of this study was to investigate the effectiveness of alkali and steim treatment to both the sugarcane bagasse fibers and rice husk on flexural properties of the PLA composites. Composites were prepared in a various composition range of rice husk content $(0,5,10 \mathrm{wt} . \%)$ added to $25 \mathrm{wt} . \%$ sugarcane bagasse-PLA composites. Structural 
evaluation using SEM was performed to understand the reinforcement and the effect of fiber characteristics on the failure mechanism and properties of the composites.

\section{Experimental}

Materials and Compression Molding. The PLA used in the experiment was obtained from TAMIYA in the form of PLA-sheet in B4 size with a thickness of $0.3 \mathrm{~mm}$. PLA sheet was cut into $25.8 \times 18.25 \mathrm{~cm}^{2}$. The sugarcane bagasse fibers were supplied by a local sugar mill factory, P.T. Candi Baru in Sidoarjo, Indonesia (Fig. 1). Meanwhile the rice husk (Fig. 2) was obtained from a rice paddies milling factory in Sidoarjo, Indonesia. Both the bagasse and the husk were first soaked in $70 \%$ ethanol solution for one-hour neutralization process to kill the bacteria which can cause fermentation and bad odor. After neutralization, they were air dried for 24 hours before treatment was carried out. The bagasse was given alkali treatment using $8 \mathrm{wt} . \% \mathrm{NaOH}$ at room temperature for one hour. Completing the treatment, the bagasse was rinsed with water few times until the $\mathrm{pH}$ of the last rinsed water achieved $\mathrm{pH}$ around 7 and then followed with oven dried at $60^{\circ} \mathrm{C}$ for 48 hours.

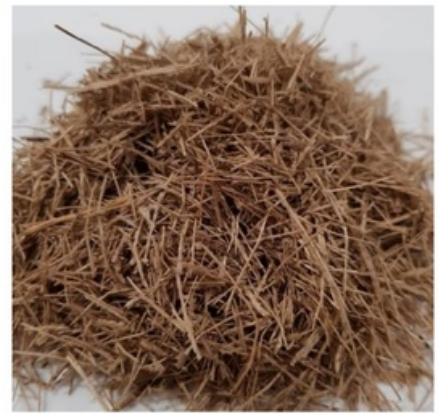

Figure 1 As-sieved sugarcane bagasse fibers

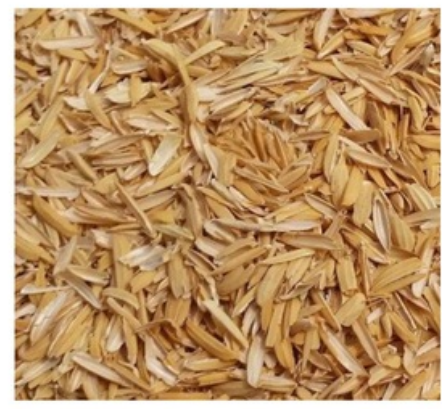

Figure 2 As-received rice husk

Steam treatment using a pressure cooker was applied to the rice husk and sugarcane bagasse fiber at $0.75 \mathrm{MPa}$ for 30 minutes. The treated rice husk and bagasse were drained and then oven dried at $60^{\circ} \mathrm{C}$ for 6 hours. Both the bagasse and rice husk (cutting was required along its axis) were sieved to obtain a size of less than 12 mesh $(1.68 \mathrm{~mm})$. The wt. \% ratio of bagasse/PLA was $25 / 75$ and the rice husk content added to bagasse/PLA was 5 and $10 \mathrm{wt}$. \%. Table 1 shows the composition of the composites prepared for testing and evaluation.

Table 1 Composition of Sugarcane Bagasse-Rice Husk - PLA Composite

\begin{tabular}{ccccc}
\hline $\begin{array}{c}\text { Sample } \\
\text { Name }\end{array}$ & Treatment & $\begin{array}{c}\text { Sugarcane Bagasse } \\
\text { [wt. \%] }\end{array}$ & $\begin{array}{c}\text { Rice Husk } \\
{[\text { wt. \%] }}\end{array}$ & $\begin{array}{c}\text { PLA } \\
\text { [wt. \%] }\end{array}$ \\
\hline S.A & & 25 & 0 & 75 \\
S.B & Steam & 25 & 5 & 70 \\
S.C & & 25 & 10 & 65 \\
N.A & & 25 & 0 & 75 \\
N.B & NaOH & 25 & 5 & 70 \\
N.C & & 25 & 10 & 65 \\
U.A & & 25 & 0 & 75 \\
U.B & Untreated & 25 & 5 & 70 \\
U.C & & 25 & 10 & 65 \\
\hline
\end{tabular}

Sugarcane bagasse and rice husk were weighed ( $200 \mathrm{~g}$ total) according to the composition shown in Table 1. Both bagasse and rice husk were mixed manually and placed between the PLA sheets to make a sandwich (Fig. 3). The prepared sandwich was hot pressed using compression molding 
machine at $190^{\circ} \mathrm{C}$ with a pressure of $165 \mathrm{kPa}$ for 6 minutes holding time and turned the sandwich over and pressed at the same pressure, temperature for another 6 minutes. The composite panels were then cut into dimension of flexural test specimen in accordance with ASTM D 790-2017.

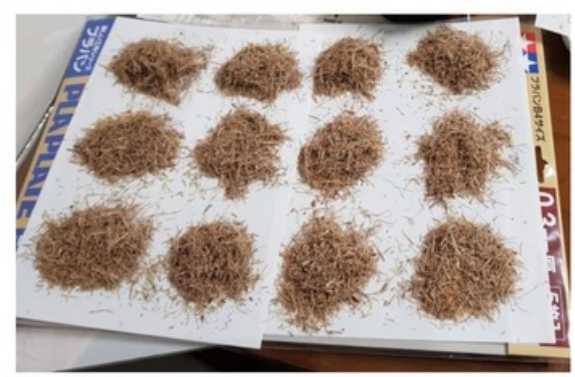

Figure 3 A mixture of bagasse and rice husk was placed on top of PLA sheet to make a sandwich

Samples Testing and Evaluation. Flexural test samples were measured their thickness and weight. Composites thickness was measured using micrometer Mitutoyo. Measurement was taken at five different positions on each sample of every composition. The weight of the samples was measured with a Mettler Toledo A0204 analytical scale. Using data of weight and area (length $\mathrm{x}$ width) measured from flexural test specimens, the area density of each specimen was calculated in concern related to lightweight property. Flexural properties were characterized by three point bend test using Shimadzu with a capacity of $50 \mathrm{kN}$ at Polymer Technology Center in Tangerang (1ndonesia). The flexural test was done at a pressure speed of $0.764-1.306 \mathrm{~mm} / \mathrm{menit}$. The characteristics of the fibers and the structure, as well as the deformation mechanism of the composites were studied by SEM (FEI type Inspect S50) at Department of Materials and Metallurgical Engineering, Sepuluh Nopember Institute of Technology, Surabaya, Indonesia. Micrographs were recorded on flexural fracture surfaces.

\section{Results and Discussion.}

The results of this study were explained in several sections. First section discussed the sample thickness and area density. These two data are important in comparison with the specification data of current materials used as automotive interior parts, such as package tray by the automotive industry. Neat PP and composites made from wood particle (30 wt.\%) reinforced PP and PE (polyethylene) were used as reference materials. Composite of $25 \mathrm{wt} \%$ sugarcane bagasse/PP from Anggono et al. (2018) in which the sugarcane bagasse were treated wit/g10 vol. \% $\mathrm{NaOH}$ solution at $70^{\circ} \mathrm{C}$ for 2 hours was also compared [15]. Flexural properties were analyzed in the next section followed by SEM evaluation on the composites structure.

Composites Thickness and Area Density. Figures 4 and 5 show the thickness and area density of composites with different fiber treatments and composition. Steam treatment given to baggase fibers results in a larger reduction of composite thickness ( $7.6 \%$ ) compared with the thickness of composites using natural fibers which were treated with alkali solution $(6.4 \%)$. The addition of steam treated rice husk added to bagasse/PLA mixture results in further reduction in thickness as shown in samples SB, SC, NB, and NC. The further reduction in thickness from steam treatment might have caused by further loss of constituent components of bagasse fibers and rice husk. The rate of dissolution is different between alkali and steam treatment applied to the bagasse. However, composition analysis on the treated fibers was not further analyzed. Ndazi et al. (2007) who studied the steam treated rice 10 isk reported the presence of cellulose, wax, and silica [22].

The area density increase with fiber content follows the rule of mixtures. Density of untreated sugarcane bagasse is $1.20 \mathrm{~g} / \mathrm{cm}^{3}$ [23], the rice husk has a bulk density in a range of $0.86-1.14$ $\mathrm{g} / \mathrm{cm}^{3}$ [24]. Fig. 5 indicates the decrease in composites area density with the addition of rice husk from 5 to $10 \mathrm{wt}$. \%. The area density continues to decrease when the bagasse experienced steam 
treatment than alkali treatment. The density of the natural fibers after treatment reduces due to the partial degradation of cellulose and complete degradation of both hemicelluloses and lignin in the treated fibers. The higher area density values of steam treated and alkali treated bagasse composites might indicate better wetting of PLA on the bagasse and rice husk present in the structure. The PLA 2 self might have penetrated into the fibers which removed most of the remaining pores inside the fibers which could have increased the density of the treated fibers and hence that of their composites. $\mathrm{O}_{2}$ the other hand, lower theoretical density values of composites with untreated bagasse fibers are due to the reported low density values of as-received fiber which is also the case for other natural fiber containing polymer composites [25]. In comparison with PP and woodboard which they are the current materials used by the automotive industry as interior parts, the area density of the studied sample is quite promising. But when compared with the bagasse/PP composites from the study of Anggono et al. (2018), the alkali treatment done at $70^{\circ} \mathrm{C}$ shows higher dissolution rate than at room temperature. This is indicated by lower area density obtained compared with that of sample NA.

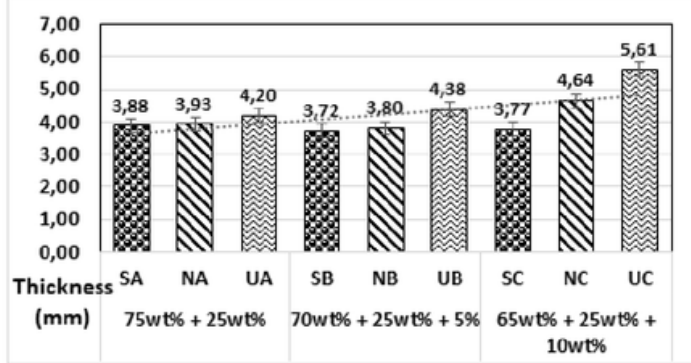

Figure 4 Composite thickness measured from different sugarcane bagasse and rice husk content

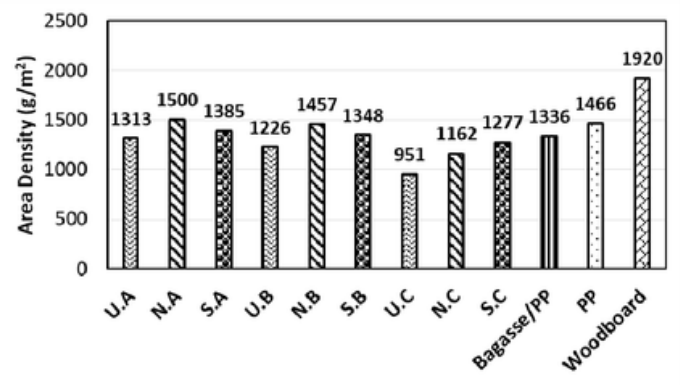

Figure 5 Area density of composites in various composition in comparison with bagasse/PP from previous research and neat PP and wordboard composites from the industry

Flexural Strength. Flexural strength is plotted against different treatments and rice husk content as shown in Fig. 6. The highest flexural strength obtained when the bagasse fibers used in the composites treated with $\mathrm{NaOH}$ than with steam treatment. It is clearly shown in Fig. 7 that the highest strength was attained when no rice husk addition in the bagasse/PLA mixture. The alkali treatment using $8 \mathrm{wt}$. \% $\mathrm{NaOH}$ increase the strength of the fibers [26] ${ }_{6}$ However another study reported that the steam treated rice husk reinforced phenol formaldehyde provide a better modulus of rupture and elasticity

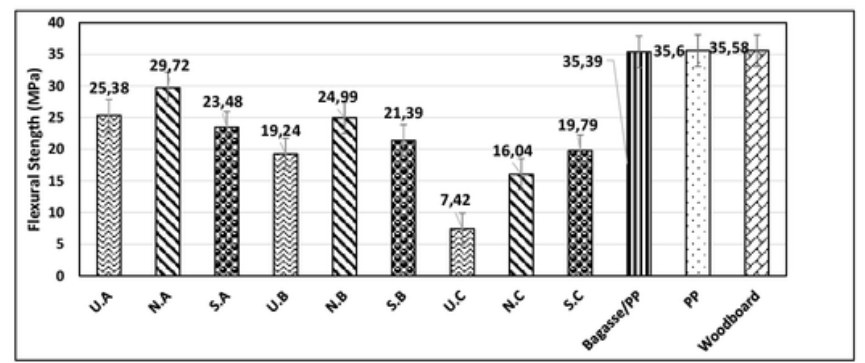

Figure 6 Flexural strength versus different treatment and rice husk content 


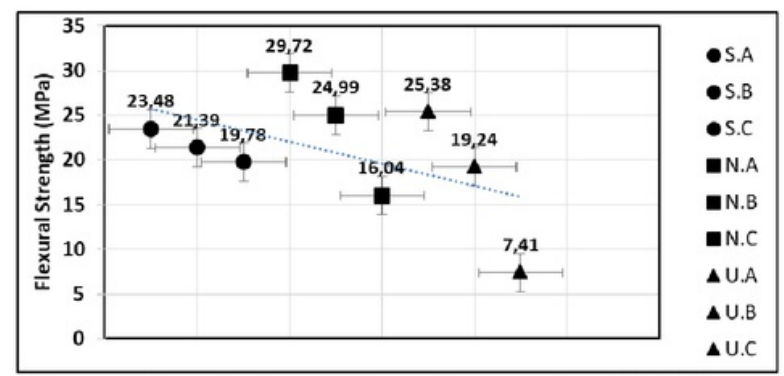

Figure 7 Correlation of flexural strength with different treatment and rice husk content

Structural Characterization. Figures 8 a) to c) display the structure from the cross section of fractured area of flexural test samples. The structure shown in micrographs Fig. 8 a) and b) shows that the bagasse fiber fracture is more dominant than fiber pull-out. The lower flexural strength obtained in the composites with steam treated bagasse fibers can be the result in weakening the fiber strength due to steam treatment. Fiber pull-out was found in Figure 8c) as a result of debonding in composites with untreated bagasse fibers due to weak interfacial adhesion between fiber and PP matrix.

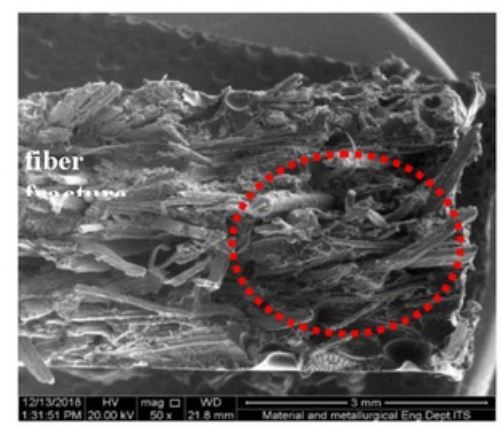

a)

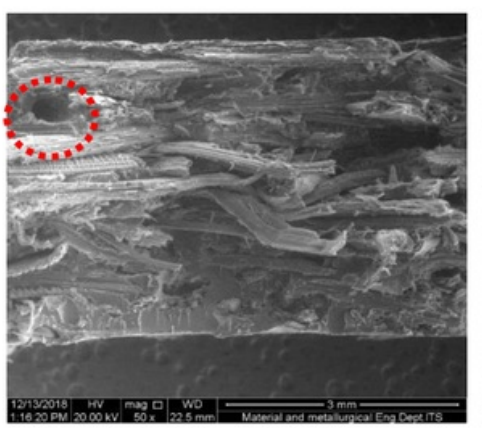

b)

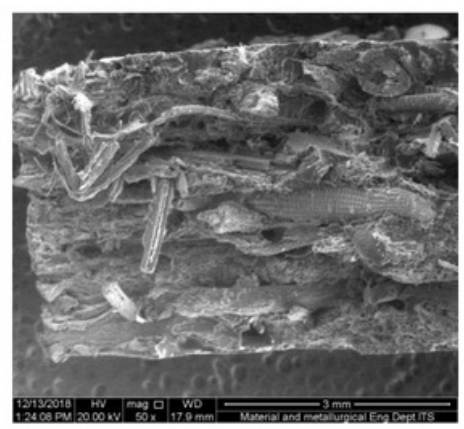

c)

\section{Summary}

The results on alkali treatment on bagasse fibers produce better flexural strength of PLA composites compared to the use of steam treated fibers. The addition of steam treated rice husk lower the composite strength even further.

\section{8}

\section{Acknowledgements}

The authors thank the Ministry of Research, Technology and Higher Education of 15 public of Indonesia for the research funding under grant no. 002/SP2H/LT/MONO/L7/2019. PT. Candi Baru Sugar Mill Factory (Indonesia) is acknowledged for providing the sugarcane bagasse fibers. The authors were grateful for the assistance of Russava Istiani with the use of SEM at Sepuluh Nopember Institute of Technology, Surabaya.

\section{References}

1. L. Dányádi, K. Renner, Z. Szabo, G. Nagy, J. Móczó and B. Pukánszky, Polym. Adv. Technol. 17 (2006) 967-974. 
2. L. Dányádi, K. Renner, J. Móczó and B. Pukánszky, Polym. Eng. Sci. 47(8) (2007) 1246-1255.

3. J. Anggono, Á. E. Farkas, A. Bartos, J. Móczó, Antoni, H. Purwaningsih, and B. Pukánszky, Eur. Polym. J., 112 (3) (2019) 153-160.

4. K. Renner, C. Kenyó, J. Móczó, and B. Pukánszky, Composites, Appl. Sci. Manuf. A41(11) (2010) 1653-1661.

5. R. Csizmadia, G. Faludi, K. Renner, J. Móczó, B. Pukánszky, Composites, Appl. Sci. Manuf. A53 (2013) 46-53.

6. J. Gassan, A.K. Bledzki, Compos. Sci. Technol. 59(9) (1999) 1303-1309.

7. A. Valadez-Gonzalez, J.M. Cervantes-Uc, R. Olayo, Compos B: Eng, 30 (1999) 321.

8. D. Ray, B.K. Sarkar, A.K. Rana, N.R. Bose, Bull Mater Sci, 24 (2001) 129.

9. S. Mishra, M. Misra, S.S. Tripathy, S.K. Nayak, A.K. Mohanty. Macromol Mater Eng. 286 (2001)107.

10. K. Joseph, S. Thomas, Polymer 37 (1996) 5139.

11. I. van de Weyenberg, J. Ivens, A. De Coster, B. Kino, E. Baetens, I. Vepoes, Compos Sci Technol. 63 (2003) 1241.

12. J. Anggono, et al., submitted to E3S Web of Conferences (2019).

13. L.Y. Mwaikambo, M.P. Ansell, Compos. Sci. Technol. 63 (9) (2003) 1297-1305.

14. S.S. Munawar, K. Umemura, S. Kawai, J. of Wood Science 54 (5) (2008) 369-376.

15. J. Anggono, S. Sugondo, R. Alim, H. Purwaningsih, A. Wibawa, Mater. Sci. Forum, 923 (2018) 40-46.

16. A.K. Bledzki, A.A. Mamun, Volk, J. Compos. Sci. Tech. 70 (2010) 840-846.

17. N. Petchwattana and S. Covavisaruch, J. of Bionic Eng. 10 (2013) 110-117.

18. Information on $\mathrm{http}: / / \mathrm{www}$.fao.org/3/x0513e/x0513e21.htm retrieved on 7 April 2019

19. Information on https://www.statista.com/statistics/255945/top-countries-of-destination-for-usrice-exports-2011/ retrieved on 29 June 2019.

20. P.J. Van Soest, R.H. Wine, J. Assoc. Off. Anal. Chem. 50 (1967) 50-55

21. S.M. Luz, A.R. Gonçalves, and A.P. Del'Arco, Jr., Composites Part A: App. Sc. and Manf., 38 (2007) 1455-1461.

22. B.S. Ndazi, S. Karlsson, J. V. Tesha, and C. W. Nyahumwa, Compos. Part A: Appl. Sci. \& Manuf. 38 (2007) 925-935.

23. Information on http://www.sugartech.co.za/density/index.php retrieved on 30 June 2019.

24. K.G. Mansaray and A. E. Ghaly, Energy Sources, 19 (9) (1997) 989- 1004.

25. G. Excoffier, B. Tousasaint, M.R. Vignon, Biotechnol. Bioenergy, 38 (1991) 1308-1317

26. A. Bartos, et al., submitted to Carbohydrate Polymer Journal (2019). 
The Strength of Polylactic Acid Composites Reinforced with Sugarcane Bagasse and Rice Husk

ORIGINALITY REPORT

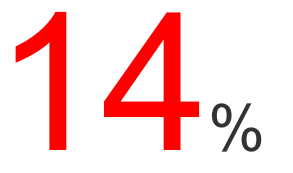

SIMILARITY INDEX
$5 \%$

INTERNET SOURCES
$14 \%$

PUBLICATIONS
$4 \%$

STUDENT PAPERS

1 Faludi, G., G. Dora, K. Renner, J. Móczó, and B.

Pukánszky. "Biocomposite from polylactic acid and lignocellulosic fibers: Structure-property correlations", Carbohydrate Polymers, 2013.

Publication

2 Brugnago, R.J.. "The effect of steam explosion on the production of sugarcane bagasse/polyester composites", Composites Part A, 201104

Publication

3 ecommons.usask.ca Internet Source

4 Omar Faruk, Mohini Sain. "Preface", Elsevier BV, 2015

5 Juliana Anggono, Ágnes Elvira Farkas, András Bartos, János Móczó, Antoni, Hariyati Purwaningsih, Béla Pukánszky. "Deformation and failure of sugarcane bagasse reinforced 
PP", European Polymer Journal, 2019

Publication

6 M. Bassyouni, S. Waheed UI Hasan. "The use of rice straw and husk fibers as reinforcements in composites", Elsevier BV, 2015

Publication

$7 \quad$ www.demeter.org.es

Internet Source

8 www.foodandnutritionjournal.org

Internet Source

9 Renner, K.. "Micromechanical deformations in

PP/lignocellulosic filler composites: Effect of matrix properties", Composites Science and

Technology, 201007

Publication

10 Cellulose Fibers Bio- and Nano-Polymer

Composites, 2011.

11 puslit2.petra.ac.id

Exclude quotes

On

Exclude bibliography

On

Exclude matches

$<1 \%$ 